\title{
Analysis on Wheel-Ground Contact Load Characteristics of Unmanned Off-road Vehicles
}

\author{
Feng Ren ${ }^{1,2,3}$, Longhai Li ${ }^{1}$, Zhengying Jiang ${ }^{1 *}$, Tao Song ${ }^{2}$, Xun Gong ${ }^{3}$, Yaowu Shi ${ }^{2}$ and Boliang Liu ${ }^{4}$ \\ ${ }^{1}$ School of Engineering, Changchun Normal University, Changchun 130022, China \\ ${ }^{2}$ School of Mechanical Science and Engineering, Jilin University, Changchun 130022, China \\ ${ }^{3}$ Jiangsu LiuGong Machinery Co., Ltd, Jiangsu 545007, China \\ ${ }^{4}$ School of Engineering, University of Toronto, Ootario M5S1A1,Canada
}

Received 3 April 2017; Accepted 20 July 2017

\begin{abstract}
The wheel-ground contact load characteristics of unmanned ground vehicles are an important foundation for vehicle design, structural parameter optimization, off-road performance evaluation, and control strategy formulation. The load characteristics of unmanned ground vehicles are mainly investigated based on traditional vehicle terramechanics theory, which cannot reflect wheel-ground contact. This study proposed a model integrated with qualitative theoretical analysis and quasi-quantitative simulation to evaluate wheel-ground contact load characteristics during the off-road movement of unmanned vehicles. Prediction and test models of system wheel contact load characteristics were built by multi-physical field coupling analysis. Flow and power characteristics during unilateral steering were discussed systematically through terramechanics theory. The accuracy of the models was verified by experiments. Results show that changes in the tire load affect the average stress on the ground contact surface of tire, which leads to the forward gravity center of the entire machine. The optimal combination of structural parameters under dynamic working conditions of the unmanned vehicles is determined based on multi-physics coupling analysis model to optimize the structural design. The load pressure of the system reaches $19.53 \mathrm{MPa}$ in the accelerated start-up phase, and the error of simulation and test results is within $10 \%$. This study provides tools for theoretical and simulation analysis for development of the optimized structure design and control strategy formulation of unmanned ground vehicles.
\end{abstract}

Keywords: Unmanned vehicles, Dynamic characteristics, Multi-physics coupling analysis

\section{Introduction}

Operating in a dangerous environment is the bounded duty of unmanned vehicles, rather than human beings. Unmanned vehicles are necessary in dangerous and complicated terrain conditions, such as nuclear power plants with high radiation levels, dangerous disaster assistance sites, hazardous geological mining, transportation of materials and ammunition for army forces in mountainous areas, and environmental investigation of battlefield.

With increasing application of unmanned platforms, research on related technology has considerably progressed; in particular, research on the lunar rover and Mars explorer has achieved satisfactory results. In foreign countries, Carnegie Mellon University, Stanford University, and Massachusetts Institute of Technology conducted extensive research in this field [1-3]. Military ground unmanned platforms in China have been increasingly investigated due to serious technical barriers and blockade. The key technology research on military ground unmanned platforms was performed to meet the requirements of modern warfare. Related technologies have been developed in Harbin

\footnotetext{
E-mail address: rffust@126.com

ISSN: $1791-2377$ @ 2017 Eastern Macedonia and Thrace Institute of Technology. All rights reserved. doi:10.25103/jestr.103.14
}

University, Jilin University, Zhejiang University, Beijing University of Technology, and Weapon 201 for unmanned platforms. However, existing research was performed under ideal conditions without simulating the real battlefield environment, resulting in significantly obsolete results in relation to the demands. Most studies on unmanned mobile vehicles in the structural environment are still in the twodimensional obstacle avoidance stage, and these vehicles show insufficient satisfactory adaptive capacity in 3D nonstructural terrains. Therefore, many scholars have investigated the basic theories of unmanned ground vehicles for military use. Wong studied the basic theory of ground mechanics and established a basic mechanical model of slipsteering track-laying vehicles [4]. Yi et al. investigated the navigation algorithm of slip-steering robot with four wheels [5]. Helmick et al. studied the path planning problem of unmanned vehicles by using the slip-compensated model [6] These studies focused on the load characteristics of wheelground contact. Hence, the load characteristics of unmanned vehicles during off-road walking must be investigated.

\section{State of the art}

American scholars first studied the basic vehicle-ground interaction theories. Professor Bekker established the basic theory of ground mechanics, theoretically investigated the 
sinkage and driving resistance of vehicles, and systematically evaluated the tire-ground interaction by testing. This theory provides the foundation for analyzing the load characteristics of vehicles and ground by applying mechanical methods. However, this theory only focuses on the tire-ground point contact, which significantly differs from the real load characteristics [7]. Professor J.Y.Wong, a Canadian Chinese researcher, deduced the track-laying vehicle-ground interaction based on friction theory and analyzed the steering characteristics of vehicles under different turning radii [8]. This study only focused on the hard surface and assumed the lack of surface deformation during the tire-ground contact. Bruce Maclaurin et al. examined the slip behavior of track-laying vehicles by using a magic formula and proved the feasibility of the magic formula for rubber tires to slip steering vehicles [9-10]. However, they did not analyze the load characteristics of wheeled vehicles. The load characteristics of tracked vehicles are completely different from those of wheeled vehicles. Jesus morales et al. discussed the load characteristics of tracked vehicles during slip steering [11-12] and analyzed the system load characteristics through pressure features. However, they quantitatively analyzed a single parameter and did not examine the load characteristics of multiple parameters. Lei et al. from the Beijing Institute of Technology performed a simulation analysis on the steering characteristics of armored tracked vehicles [13] but did not analyze the influence of ground parameters on the performance of the entire machine. Karafiath analyzed the steering and slip performances of tires on soft surface but did not analyze the coupling relationship between the ground and structural parameters of the entire machine. The tire-soil mechanical model proposed by Darius et al. revealed the complicated interaction between the tire and soil. Hence, the tire-soil mechanics for ground and unmanned off-road engineering vehicles that frequently operate in different environments must be analyzed [14-15]. Savitski, D et al. analyzed the tire-ground contact features of wheeled offroad vehicles and investigated the slip characteristics of vehicle tires on nonstructural road surface [16-21]. This study provided a basis for investigation of the tire-ground contact features of unmanned vehicles.

This research focuses on the Mars rover and lunar rover, which are generally small and ground unmanned platform weight between 1.5-10 t. The weight of unmanned ground vehicles generally ranges between 1.5-10 t. The compression behavior and shear properties of the platform-ground contact significantly differ from those of robots, such as moon rovers. Few studies are reported regarding the load characteristics during the wheel-ground interaction of unmanned ground vehicles. Unmanned vehicles operate in dangerous environments, where slippage and sinkage frequently occur, and cannot be studied using the traditional theory of ground mechanics, which is the Bekker formula of pressure resistance. Thus, a method for theoretical study and online prediction of wheel-ground contact characteristics must be developed.

A theoretical model for calculating wheel-ground contact load characteristics was constructed based on the ground mechanics and multi-body dynamics, and the corresponding influencing factors were analyzed. The influences of ground parameters on the performance of the entire platform, especially on the structural parameters of the machine, were analyzed. A multi-physics coupling analysis model was established for the entire platform. This model could be an effective tool for research and development.

The rest of this paper is organized as follows. Section 3 describes the prerequisites for kinematic model analysis of unmanned ground vehicles and establishes a theoretical analysis model. Section 4 summarizes the pressure, flow, and a power characteristic during unilateral steering based on the multi-physics coupling analysis model and verifies them through experiment. Section 5 provides the conclusions.

\section{Methodology}

\subsection{Theoretical model}

Several hypotheses are drawn when the kinematic model of unmanned vehicles was established:

(1) Slippage and slide are ignored for unmanned vehicles operating on firm ground.

(2) A certain relationship existed between the shear stress and shear displacement. The initial position is selected at the tire-ground contact point.

(3) The shear stress at any tire-ground contact point is opposite with the slippage velocity of the point.

The kinematics analysis of the vehicle during turning is shown in Fig. 1. Point $O_{1}$ is the instant rotation center of the vehicle. In this study, the right front wheel of the vehicle was analyzed as an example. The relative coordinate system of the right front wheel is $x_{1} y_{1}$, and the center of the right front wheel is origin $O_{1}$. On the $\mathrm{Y}$ direction, the longitudinal offset of $C G$ and $O O_{1}$ is $s_{0}$.

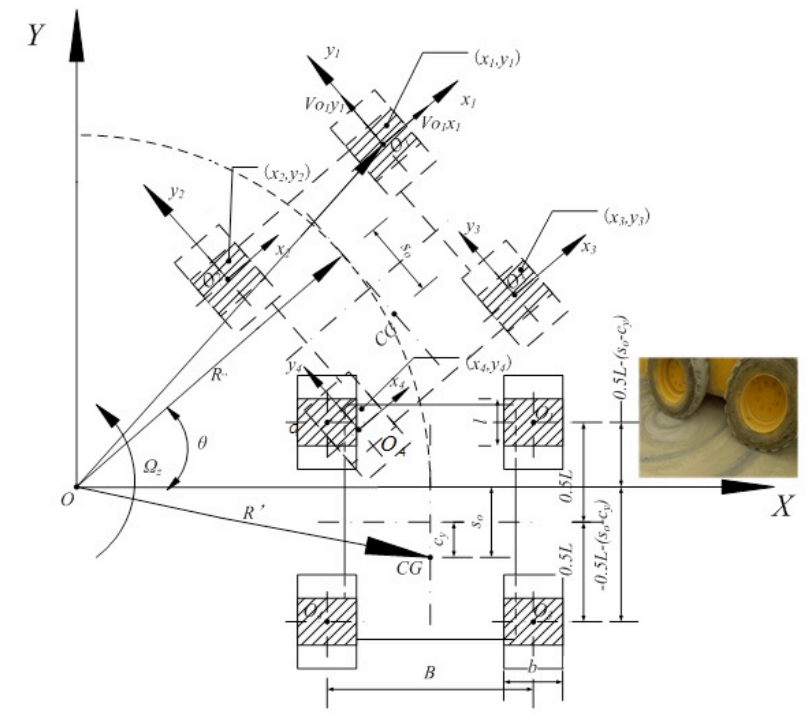

Fig. 1. Rotational kinematics of the vehicle

When the unmanned vehicles rotate around $O$ at the angular velocity $\Omega_{Z}$, the velocity at the axial center of the right front wheel $O_{1}$ is:

$$
\begin{aligned}
& V_{O 1}=R^{\prime \prime} \Omega_{z}=\sqrt{\left(R^{\prime \prime}+\frac{B}{2}\right)^{2}+\left(\frac{L}{2}-S_{o}+c_{y}\right)^{2}} \Omega_{Z} \\
& V_{O_{1} x_{1}}=R^{\prime \prime \prime} \Omega_{Z} \sin \alpha=\left(\frac{L}{2}-S_{o}+c_{y}\right)
\end{aligned}
$$


The rotational angular velocity of the right wheel is $\omega_{0}$. The slip velocities of the projection point $\left(y_{1}\right)$ of $O_{1}$ on the wheel-ground contact surface along $y_{1}$ and $x_{1}$ are:

$V_{t_{1} x_{1}}=\left(R^{\prime \prime}+\frac{B}{2}\right) \Omega_{Z}-r \omega_{o}$

$V_{t_{1} x_{1}}=\left(\frac{L}{2}-S_{O}+c_{y}\right) \Omega_{Z}$

Any point $\left(x_{1}, y_{1}\right)$ on the left front wheel-ground contact surface was analyzed. The longitudinal and transverse velocity components of $\left(x_{1}, y_{1}\right)$ in relative to $O_{t_{1}}$ can be expressed by $x_{1} \Omega_{z}$ and $y_{1} \Omega_{z}$, respectively, because the wheel rotated around $O$ at the angular velocity $\Omega_{Z}$.

In summary, the shear displacements of points $\left(x_{1}, y_{1}\right)$ and $\left(x_{2}, y_{2}\right)$ on the left and right front wheels are:

$$
\left[\begin{array}{l}
j_{o_{1}} \\
j_{o_{2}} \\
j_{o_{3}} \\
j_{o_{4}}
\end{array}\right]=\left[\begin{array}{l}
\int_{0}^{t} v_{o_{o_{1}}} d_{t} \\
\int_{0}^{t} v_{{o_{o}}_{2}} d_{t} \\
\int_{0}^{t} v_{j_{o_{3}}} d_{t} \\
\int_{0}^{t} v_{j_{o_{4}}} d_{t}
\end{array}\right]=\left[\begin{array}{l}
\left(\frac{v}{r w}-1\right)\left(\frac{l}{2}-y_{1}\right) \\
\left(\frac{v}{r w}-1\right)\left(\frac{l}{2}-y_{2}\right) \\
\left(\frac{v}{r w}-1\right)\left(\frac{l}{2}-y_{3}\right) \\
\left(\frac{v}{r w}-1\right)\left(\frac{l}{2}-y_{4}\right)
\end{array}\right]
$$

When the vehicle is skid-steering around $O$ at the angular velocity $\Omega_{z}$, the rotational velocities of centers for four wheels around $O$ are:

$$
\left[\begin{array}{l}
V_{O_{1}} \\
V_{O_{2}} \\
V_{O_{3}} \\
V_{O_{4}}
\end{array}\right]=\left[\begin{array}{l}
R^{\prime \prime \prime} \\
R^{\prime \prime \prime} \\
R^{\prime \prime \prime \prime} \\
R^{\prime \prime \prime \prime}
\end{array}\right] \Omega_{z}=\left[\begin{array}{l}
\sqrt{\left(R^{\prime \prime}+\frac{B}{2}\right)^{2}+\left(\frac{L}{2}-S_{o}+c_{y}\right)^{2}} \\
\sqrt{\left(R^{\prime \prime}-\frac{B}{2}\right)^{2}+\left(\frac{L}{2}-s_{o}+c_{y}\right)^{2}} \\
\sqrt{\left(R^{\prime \prime}+\frac{B}{2}\right)^{2}+\left(\frac{B}{2}\right)^{2}+\left(\frac{L}{2}+s_{o}+c_{y}\right)^{2}}
\end{array}\right]
$$

where $R^{\prime \prime}(\mathrm{m})$ is the radius of rotation of point $O_{1}$ around the instantaneous steering center, $R^{\prime \prime}(\mathrm{m})$ is the radius of rotation of point $O_{2}$ around the instantaneous steering center, $R^{\text {"'m }}(\mathrm{m})$ is the radius of rotation of point $\mathrm{O}_{3}$ around the instantaneous steering center, $R^{\mathrm{m} \prime}(\mathrm{m})$ is the radius of rotation of point $O_{4}$ around the instantaneous steering center, $\Omega_{z}(\mathrm{rad} / \mathrm{s})$ is the rotational angular velocity of the skid-steering vehicle around the instantaneous steering center, $R^{\prime \prime}(\mathrm{m})$ is the radius of rotation of point $O_{v}$ around the instantaneous steering center, $c_{y}(\mathrm{~m})$ is the longitudinal offsets of the geometric center and the center of gravity of the vehicle, $B(\mathrm{~m})$ is the tread of the skid-steering vehicle, $L(\mathrm{~m})$ is the wheel base of the skid-steering vehicle, and $S_{O}$ is the longitudinal offset distance between the center of gravity $C G$ and the connection line of the instantaneous steering and external tire rotational centers.

Based from the above theoretical model, the key parameters of the entire machine are connected with the ground characteristic parameters, and the dynamic characteristics of the entire machine can be analyzed through different ground parameters, which provide the theoretical basis for the next simulation analysis.

\subsection{Establishment of the simulation model}

A simulation model of the entire hydraulic system was constructed through AMESim software (Fig. 2) to accurately analyze the dynamic performance of unmanned vehicles during off-road driving. The multi-body kinematics model of the entire machine was established through LMS Motion software (Fig. 3). The joint simulation was realized by the communication interfaces of the two software, and the multi-physics coupling analysis of the entire machine was implemented.

The simulation parameters, including cornering coefficient $(0.68)$, rated speed of the engine $(2400 \mathrm{r} / \mathrm{min})$, dead load of the vehicle $(3600 \mathrm{Kg})$, variable pump, platform tread $(1200 \mathrm{~mm})$, and CG height $(784 \mathrm{~mm})$, are mainly listed in Table 1. The mechanical characteristics of the entire machine are transmitted through tires and ground. The major parameters of tire and ground for multi-body kinematics modeling are shown in Table 2.

Table.1. Main parameters of the multi-physics coupling analysis model

\begin{tabular}{l|l}
\hline Parameters (unit) & Values \\
\hline Dead load of the machine $(\mathrm{kg})$ & 3600 \\
Motor displacement $(\mathrm{ml} / \mathrm{r})$ & $350 / 560$ \\
Tread $(\mathrm{mm})$ & 1200 \\
Wheelbase $(\mathrm{mm})$ & 1150 \\
Section width of tire $(\mathrm{mm})$ & 307 \\
Diameter of tire $(\mathrm{mm})$ & 830 \\
Height of CG $(\mathrm{mm})$ & 784 \\
Height of the machine $(\mathrm{mm})$ & 2050 \\
Mass of swing arm $(\mathrm{kg})$ & 300 \\
\hline
\end{tabular}

Table.2. Main parameters of the multi-body kinematics model

\begin{tabular}{l|l}
\hline Parameters & Values \\
\hline Radius of tire $/ \mathrm{mm}$ & 415.5 \\
Vertical damping coefficient $/ \mathrm{kg} / \mathrm{s}$ & 8350 \\
Rolling resistance coefficient & 0.03 \\
Friction coefficient & 0.65 \\
Cornering stiffness $/ \mathrm{m} * \mathrm{~kg} / \mathrm{s} 2 / \mathrm{rad}$ & 54000 \\
Vertical stiffness $/ \mathrm{N} / \mathrm{m}$ & 575000 \\
\hline
\end{tabular}


Feng Ren, Longhai Li, Zhengying Jiang, Tao Song, Xun Gong, Yaowu Shi and Boliang Liu/ Journal of Engineering Science and Technology Review 10 (3) (2017) 97-103

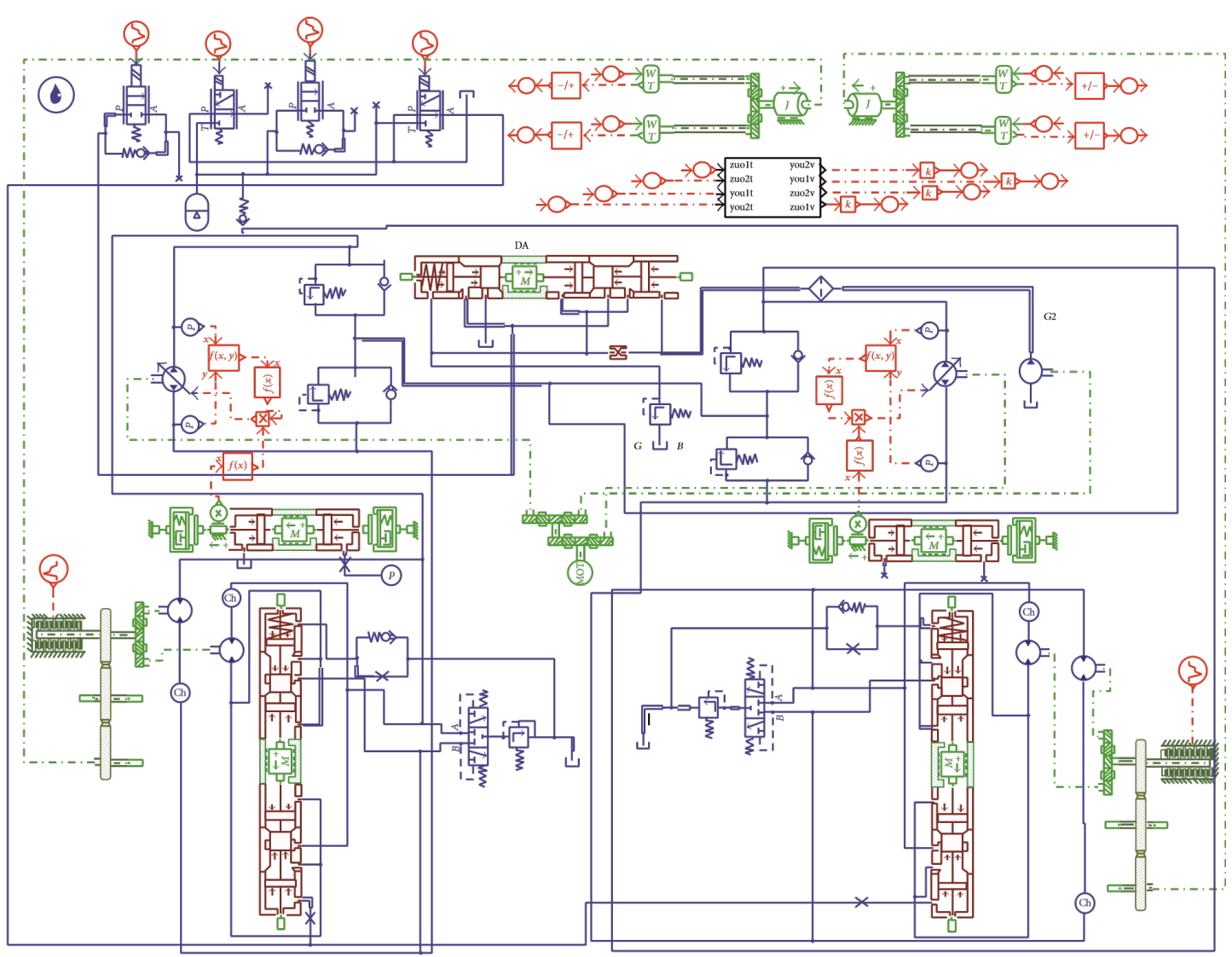

Fig. 2. Simulation model of the traveling hydraulic system

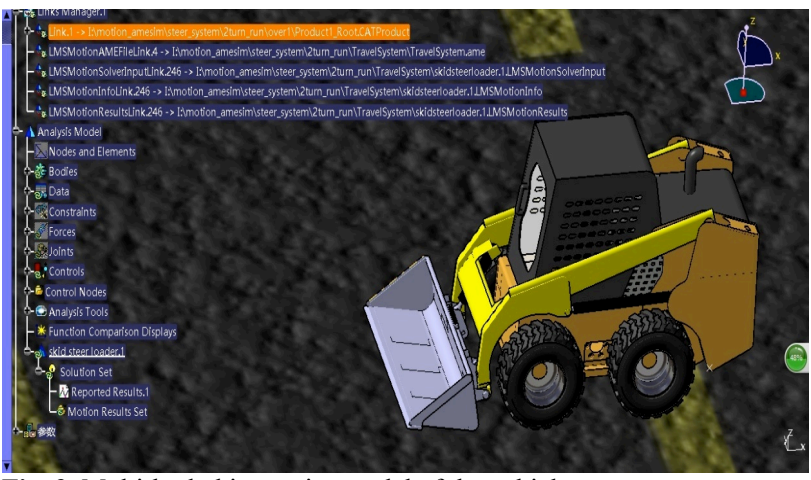

Fig. 3. Multi-body kinematics model of the vehicle

\section{Result Analysis and Discussion}

In the test, the working conditions of the unilateral steering are: the prototype is empty, the engine speed is $2400 \mathrm{r} / \mathrm{min}$, the hard ground is hard, the right wheel is cut off at the control port of the piston pump, and the input signal of the piston pump corresponding to the right wheel is not inputted. All the conditions in the simulation and test results are completed to ensure the effectiveness of the simulation results.

Pressure, flow, and power characteristic curves for the walking front and rear pumps of the unmanned vehicle under unilateral steering conditions are shown in Figs. 4 and 5.

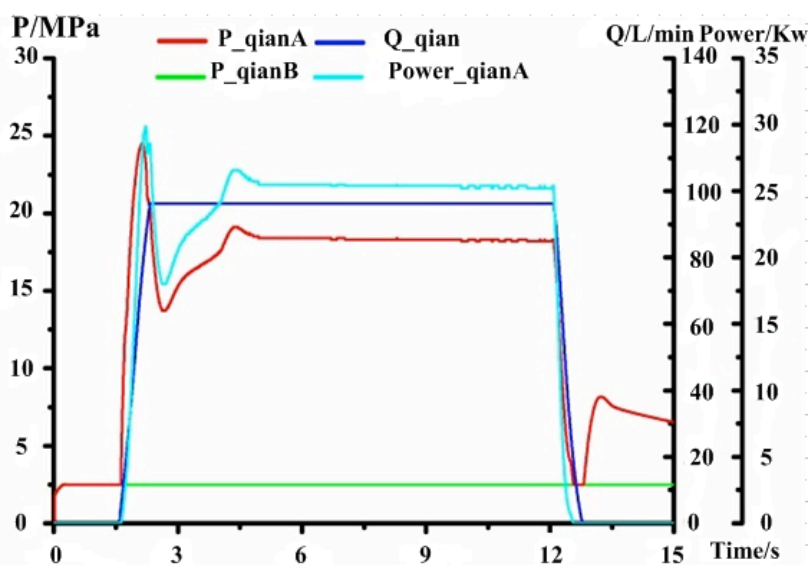

Fig. 4. Simulation curves for the front pump of the traveling hydraulic system

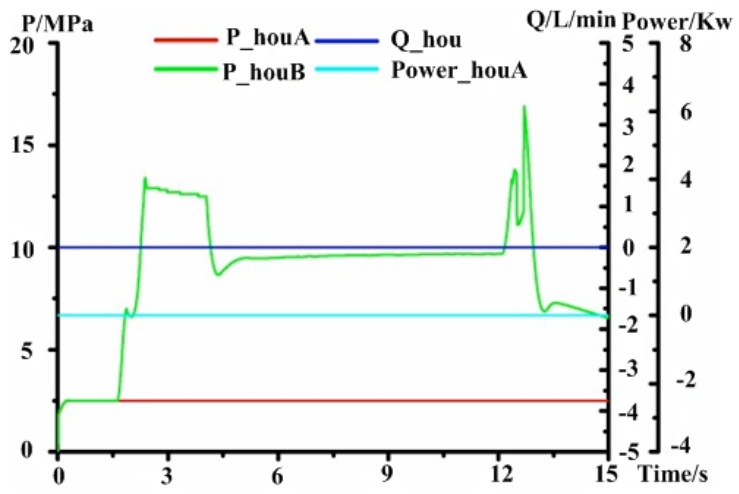

Fig. 5. Simulation curves for the rear pump of the traveling hydraulic system 
A quasi-quantitative analysis on dynamic power flow characteristics of the unmanned vehicle can be realized by the simulation model. A prototype is used in the test to verify the validity of the multi-physics coupling analysis model. The simulation and rest results will be analyzed in detail.

\subsection{Test}

To test the traveling hydraulic system, pressure sensors were installed on the variable pump, oil inlet and outlet of the walking engine, oil pump outlet and the two sides of the variable oil cylinder to measure the pressure at different points of the traveling hydraulic system. The sensor channels are listed in Table 3, and the distribution of sensors is shown in Fig. 6.

Table.3. Sensor channels

\begin{tabular}{|c|c|c|c|}
\hline $\begin{array}{l}\text { No. of } \\
\text { channels }\end{array}$ & Test point & $\begin{array}{l}\text { No. of } \\
\text { test point }\end{array}$ & Sensor range \\
\hline Channel 2 & $\begin{array}{l}\text { Pressure at the } \\
\text { front pump port B }\end{array}$ & $\mathrm{P} 2$ & $0-50 \mathrm{MPa}$ \\
\hline Channel 3 & $\begin{array}{l}\text { Pressure at the } \\
\text { rear pump port } \mathrm{A}\end{array}$ & P3 & $0-50 \mathrm{MPa}$ \\
\hline Channel 4 & $\begin{array}{l}\text { Pressure at the } \\
\text { rear pump port B }\end{array}$ & $\mathrm{P} 4$ & $0-50 \mathrm{MPa}$ \\
\hline Channel 5 & $\begin{array}{l}\text { Pressure of the } \\
\text { front pump X1 }\end{array}$ & P5 & 0-7 MPa \\
\hline Channel 6 & $\begin{array}{l}\text { Pressure of the } \\
\text { front pump X2 }\end{array}$ & P6 & 0-7 MPa \\
\hline Channel 7 & $\begin{array}{l}\text { Pressure of the } \\
\text { rear pump X1 }\end{array}$ & P7 & 0-7 MPa \\
\hline Channel 8 & $\begin{array}{l}\text { Pressure of the } \\
\text { rear pump X2 }\end{array}$ & P8 & 0-7 MPa \\
\hline Channel 9 & $\begin{array}{l}\text { Pressure at the } \\
\text { port Y }\end{array}$ & P9 & 0-7 MPa \\
\hline Channel 10 & $\begin{array}{l}\text { Pressure at the } \\
\text { multitandem valve } \\
\text { entrance }\end{array}$ & P10 & 0-7 MPa \\
\hline Channel 11 & $\begin{array}{l}\text { Output flow of the } \\
\text { front pump }\end{array}$ & Q1 & $0-150 \mathrm{~L} / \mathrm{min}$ \\
\hline Channel 12 & $\begin{array}{l}\text { Output flow of the } \\
\text { rear pump }\end{array}$ & Q2 & $0-150 \mathrm{~L} / \mathrm{min}$ \\
\hline Channel 13 & $\begin{array}{l}\text { Output flow of the } \\
\text { working pump }\end{array}$ & Q3 & $0-150 \mathrm{~L} / \mathrm{min}$ \\
\hline
\end{tabular}

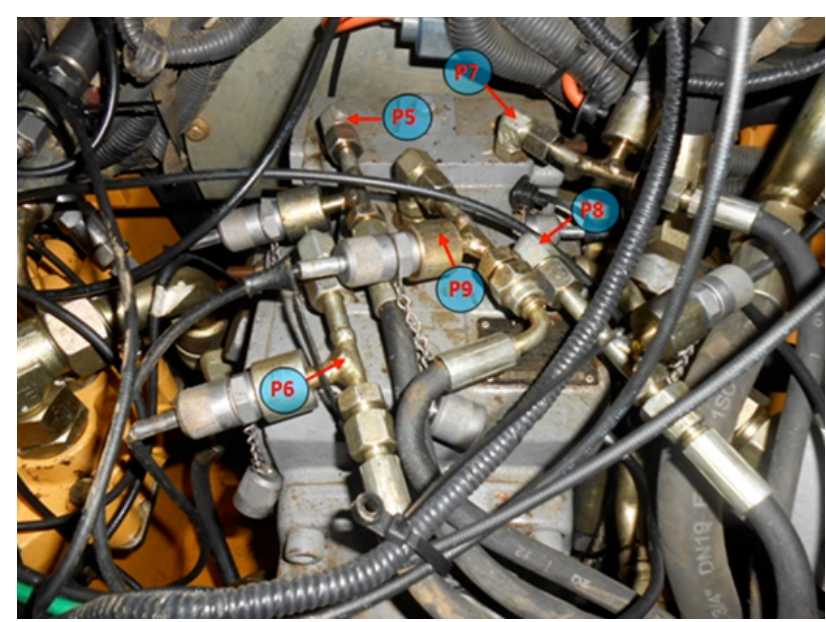

Fig. 6. Distribution of sensors

The test results are shown in Figs. 7 and 8.

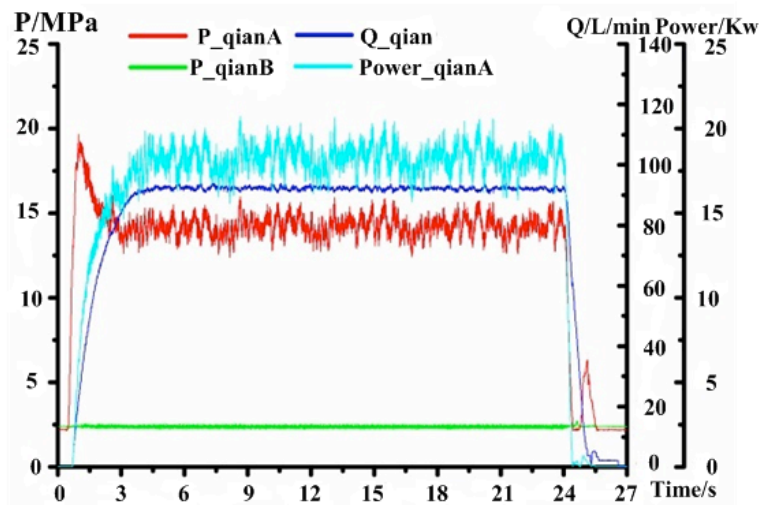

Fig. 7. Test curves for the front pump of the traveling hydraulic system

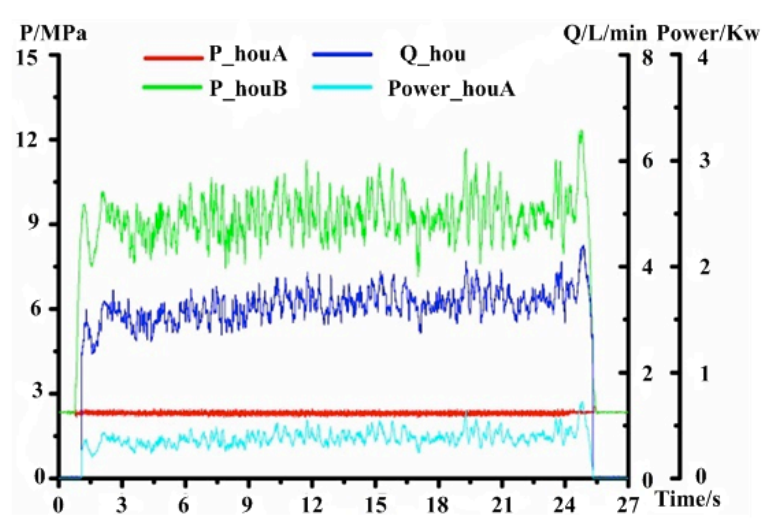

Fig.8. Test curves of the rear pump of the traveling hydraulic system

The pressure, flow, and power characteristics of the unmanned vehicle during the initial acceleration, stable walking, and braking stages are shown in Figs. 4, 5, 7 and 8. The comparison results are shown in Table 4.

Table 4. Comparison between the simulation and test results under unilateral steering conditions

\begin{tabular}{|c|c|c|c|}
\hline $\begin{array}{l}\text { Operating } \\
\text { conditions }\end{array}$ & Comparison items & $\begin{array}{l}\text { Test } \\
\text { results }\end{array}$ & $\begin{array}{l}\text { Simulation } \\
\text { results }\end{array}$ \\
\hline $\begin{array}{l}\text { Initialization } \\
\text { acceleration } \\
\text { stage }\end{array}$ & $\begin{array}{l}\text { Maximum pressure of } \\
\text { the high-pressure loop } \\
\text { /MPa } \\
\text { Time of the maximum } \\
\text { pressure of the high- } \\
\text { pressure loop /s } \\
\text { Flow rise time /s } \\
\text { Maximum power } / \mathrm{Kw}\end{array}$ & $\begin{array}{l}19.53 \\
0.55 \\
3.21 \\
20.09 \\
\end{array}$ & $\begin{array}{l}0.67 \\
0.72 \\
25.80 \\
\end{array}$ \\
\hline $\begin{array}{l}\text { Stable } \\
\text { walking } \\
\text { stage }\end{array}$ & $\begin{array}{l}\text { Pressure mean of the } \\
\text { high-pressure loop in the } \\
\text { front pump } / \mathrm{MPa} \\
\text { Pressure mean of the } \\
\text { high-pressure loop in the } \\
\text { rear pump } / \mathrm{MPa} \\
\text { Average flow } / \mathrm{L} / \mathrm{min} \\
\text { Average power } / \mathrm{Kw}\end{array}$ & $\begin{array}{l}14.56 \\
9.71 \\
90.20 \\
18.90\end{array}$ & $\begin{array}{l}18.31 \\
9.62 \\
97.68 \\
22.03\end{array}$ \\
\hline $\begin{array}{l}\text { Braking } \\
\text { stage }\end{array}$ & $\begin{array}{l}\text { Maximum pressure of } \\
\text { the high-pressure loop } \\
/ \mathrm{MPa} \\
\text { Braking time } \\
\text { consumption /s }\end{array}$ & $\begin{array}{l}12.36 \\
1.10\end{array}$ & $\begin{array}{l}16.83 \\
1.34\end{array}$ \\
\hline
\end{tabular}

The major differences between the simulation and test curves under unilateral steering conditions are: (1) the test curve showed small flow in the rear pump, and the simulation curve presented no flow. In the test, the rear pump will be locked under unilateral steering conditions and 
causes "pump motor." The variable pump is driven by the internal wheel and serves as the motor, thereby producing high-pressure oil and small flow in the hydraulic loop at the rear pump port $\mathrm{B}$. The corresponding power is called the parasitic power and is compensated by the driving power of the external wheel to the dependent variable pump. However, the simulation model cannot simulate the "pump motor" of plunger pump. (2) In the simulation curve, the pressure at the high-pressure port of the front port is higher than the test result, which is caused by the poor accuracy of wheelground mechanical parameters. No national standard on tire of unmanned vehicles exists and no delivery test is needed. Therefore, this study has insufficient effective data on parameters, such as lateral stiffness. This study mainly focused on the ranges of tire parameters in the automobile industry and related empirical values.

\section{Conclusions}

Flow, pressure, and power characteristics of the system were analyzed based on the wheel-ground contact mechanical model by combining the theoretical analysis, multi-physics coupling analysis and testing to evaluate the dynamic performances of unmanned ground vehicles and identify the load characteristics during wheel-ground interaction. The following conclusions are drawn:

(1) Based on the theoretical analysis of unmanned vehicles, the sliding speed of the entire machine is closely related to tread and wheel base. During the design process, the load characteristics during the skid-steering stage of the platform can be qualitatively analyzed by the established model.

(2) The simulation analysis of unmanned vehicles showed that the rear pump caused "pump motor" under unilateral steering conditions. Key attentions must be provided for the system matching during the design process.

(3) According to the entire machine test, the simulation results of multi-physics coupling analysis model are very close to the test results in terms of numerical values and change trend. The simulation results are applicable for study of unmanned vehicles and reduce huge labor requirement and material consumption.

The wheel-ground contact load characteristics of unmanned ground vehicles are investigated by using theoretical, simulation, and test methods. The corresponding multi-physics coupling analysis model is established, which is an effective tool for the design of wheeled unmanned ground vehicles. However, verifying the simulation results of other typical road surfaces and soil environments is necessary because the wheel-ground contact load characteristics of unmanned ground vehicles are sensitive to road surface and soil environment.

\section{Acknowledgements}

This work was supported by the National Science Foundation of China (Grant No. 51405187) and the Natural Science Foundation of Changchun Normal University.

This is an Open Access article distributed under the terms of the Creative Commons Attribution Licence

\section{References}

1.Nilanjan Chakraborty and Ashitava Ghosal., "Kinematics of wheeled mobile robots on uneven terrain". Mechanism and Machine Theory, 39(12),2004,pp.1273-1287.

2.N. Seegmiller, F. Rogers-Marcovitz, G. Miller, and A. Kelly., "Vehicle model identification using integrated prediction error minimization". International Journal of Robotics Research, 32(8) ,2013,pp.912-931.

3.Mahmoud Tarokh, Huy Dang Ho, and Antonios Bouloubasis., "Systematic kinematics analysis and balance control of high mobility rovers over rough terrain". Robotics and Autonomous Systems, 61(1),2013,pp.12-24.

4. J.Y.Wong., "Theory of Ground vehicles, 3rd edition". Hoboken: Wiley Press, America,2001,pp.230-330.

5.Jingang Yi, Hongpeng Wang, Junjie Zhang, Dezhen Song, Suhada Jayasuriya, Jingtai Liu., "Kinematic modeling and analysis of skidsteered mobile robots with applications to low-cost inertial measurement unit based motion estimation", IEEE Transactions on Robotics, 25(5),2009,pp.1087-1097.

6.D. M. Helmick, S. I. Roumeliotis, Y. Cheng, D. S. Clouse, M. Bajracharya, and L. H. Matthies, "Slip-compensated path following for planetary exploration rovers," $A d v$. Robot., 20(11),2006,pp.1257-1280.

7.Bekker MG., "Off-road locomotion: research and development in terramechanics". Michigan: The University of Michigan Press, 1960, pp.110-115.

8. J.Y.Wong, CHIANG C F., "A general theory for skid steering of tracked vehicles on firm ground". Proceedings of Institution of Mechanical Engineers, Part D: Journal of Automobile Engineering, 215(3),2001,pp.343-355.

9. Bruce maclaurin., "A skid steering model using the magic formula”. Journal of terramechanics, 48(4), 2011,pp.247-263.
10. Ding Shihong and Sun Jinlin., "Direct yaw-moment control for 4WID electric vehicle via finite-time control technique".Nonlinear dynamics,88(1),2007,pp.239-254.

11.Clarke, M. and Blanchard, T., "Development of a Control System for a Skid-Steer Amphibious Vehicle". In: Proceedings of TAROS 2010, Plymouth, United Kingdom: Intelligent Robotics Group, 2010,pp.41-46.

12. Jesus Morales, Jorge L. Martinez, Alfonso J.Garcia-Cerezo, Salvador Pedraza., "Power consumption modeling of skid-steer tracked mobile robots on rigid terrain". IEEE Transactions on Robotics . 25(5),2009,pp.1098-1108.

13. YANG Lei, MA Biao,LIHe-yan, CHEN Bao-rui., "Simulation of steering characteristic for hydrostatic drive tracked vehicle". Binggong Xuebao ,31(6),2010,pp.663-668.

14. E.Mohammadpour, M.Naraghi.,"Posture stabilization of skid steer wheeled mobile robots". In: 2010 IEEE conference on robotics, Automation and Mechatronics, Singapore, Singapore: IEEE ,2010,pp.163-169.

15. Darius Ei Pebrian, Azmi Yahya., "A new multi-purpose 4WD prime mover for oil palm plantation mechanisation". International Journal of heavy vehicle systems, 19(2),2012,pp.128-150.

16.Savitski,D, Ivanov, V., Augsburg, K., Barber, Knauder, B., Zehetner, J.,"The new paradigm of an anti-lock braking system for a full electric vehicle: experimental investigation and benchmarking". Proceedings of the Institution of Mechanical Engineers Partd-Journal of Automobile Engineering, 230(10),2016,pp.1364-1377.

17.Osinenko, P.V., Geissler, M., Herlitzius, T., "A method of optimal traction control for farm tractors with feedback of drive torque". Biosyst. Eng, 129(1),2015,pp.20-33. 
Feng Ren, Longhai Li, Zhengying Jiang, Tao Song, Xun Gong, Yaowu Shi and Boliang Liu/

Journal of Engineering Science and Technology Review 10 (3) (2017) 97-103

18.Ning Sun,Yongchun,Fang He Chen, "Tracking control for magnetic-suspension systems with online unknown mass identification". Control Engineering Practice, 58(1),2017,pp.242253.

19.Daher N, Ivantysynova M., "Yaw Stability Control of Articulated Frame Off-highway Vehicles via Displacement Controlled Steerby-wire" . Control Engineering Practice, 45(12),2015,pp.46-53.
20.Stallmann M J, Els P S., "Parameterization and modelling of large off-road tyres for ride analyses: Part 2-Parameterization and validation of tyre models". Journal of Terramechanics, 55(7), 2014,pp.85-94.

21.Ji-wung Choi, Member, IEEE, and Kalevi Huhtala., "Constrained Global Path Optimization for Articulated Steering Vehicles”. IEEE Transactionson Vehicular Technology. 65(4), 2016 , pp.1868-1879. 